The Chittagong Univ. J. B. Sci., Vol. 5(1 \&2):63-75, 2010.

\title{
INFLUENCE OF CULTURING CONDITIONS FOR OPTIMUM ANTIMICROBIAL METABOLITE PRODUCTION BY STREPTOMYCES FULVOVIRIDIS
}

\author{
M. M. UDDIN, M. N. MAHMUD, M. N. ANWAR AND M. A. MANCHUR * \\ Department of Microbiology, University of Chittagong, Chittagong-4331, Bangladesh
}

\begin{abstract}
Chili field antagonistic actinomycetes Streptomyces fulvoviridis was isolated and tested for optimum antimicrobial metabolite production. Maximum antimicrobial metabolite production was found at temperature $35^{\circ} \mathrm{C}$ and $\mathrm{pH} 8.0$ and on $4^{\text {th }}$ day of incubation in shaking condition. The medium consisting of beef extract $0.75 \%$, peptone $-0.25 \%, \mathrm{NaCl}-1.5 \%, \mathrm{KCl}-1.0 \%, \mathrm{MgCl}_{2}-1.0 \%, \mathrm{FeSO}_{4}-1.0 \%$ was screened out as suitable medium for maximum antimicrobial production supplemented individually with four carbon sources of which sucrose was found as the best carbon source. The antimicrobial metabolite was found to be stable at $\mathrm{pH}$ and temperature up to 11.0 and $100^{\circ} \mathrm{C}$, respectively. The active agent was best extracted with chloroform. The antimicrobial spectrum of the metabolite was wide and shows activity against - Shigella dysenteriae (AE 14612), Shigella sonnei (CRL, ICDDR, B), Salmonella typhi (AE14296), Vibrio cholerae (AE14748), Pseudomonas aeruginosa (CRL, ICDDR, B), Bacillus cereus (BTCC19), Staphylococcus aureus (ATCC6538), Bacillus subtilis (BTTC17) and Bacillus megaterium (BTTC18).
\end{abstract}

Key words : Antimicrobial metabolite, optimum production, Streptomyces fulvoviridis, antimicrobial spectrum.

\section{INTRODUCTION}

Antagonism is an inter-population relationship in which one population has a negative effect on another. These inhibitory organisms are called 'antagonistic' microorganisms (Atlas 1997). Such organisms may be of great practical importance, since they often produce antibiotics or other inhibitory substances, which affect the normal growth processes or survival of other organisms (Pelczar et al. 1974). Soil is a diverse medium composed of many

* Corresponding author : E-mail address: manchur69@yahoo.com 
minerals and substrates essential for metabolic pathways of prokaryotic and eukaryotic inhabitants (Dakora and Phillips 2002). There is great opportunity for discovering new groups of microorganisms with industrial and clinical importance in soil (Rondon et al. 1999).

Many groups of microorganisms like Gram-positive, Gram-negative bacteria and fungi have the ability of synthesizing antimicrobial agents. The top cultivable antimicrobial agent producers present in soil are the actinomycetes (Pandey et al. 2002). These bacteria comprise about 10 - 33\% of the total bacterial community present in soil (Osborne et al. 2000). The genus Streptomyces is responsible for the synthesis of the majority of antimicrobial agents with clinical importance (Omura et al. 2001). These microbes exhibit a vast metabolic versatility. They can complete many physiological cycles that produce intermediate molecules such as enzymes or secondary metabolites with antibacterial, antifungal and antiviral capabilities. Considering above-mentioned facts the present study was undertaken to find out and optimize the growth of antibiotic producing microbial isolates.

\section{MATERIALS AND METHODS}

\section{Isolation and purification of the antibiotic producing microorganisms Media used for isolation}

The media used for the isolation of antibiotic producing microorganisms were nutrient agar medium, oat meal agar medium and starch casein medium (Kuster and Williams 1964).

\section{Plating}

One gram of soil sample was mixed with $100 \mathrm{ml}$ of sterile water in a conical flask, shaken well with magnetic stirrer and then allowed to stand for 30 minutes for sedimentation. Necessary dilution (upto $10^{-5}$ ) was made with this mother solution. The samples $(0.1 \mathrm{ml})$ were used for inoculating $15 \mathrm{ml}$ molten medium at $45^{\circ} \mathrm{C}-50^{\circ} \mathrm{C}$ in petri plates. Then the petri plates were incubated at $37^{0} \mathrm{C}$ for about 4 to 5 days.

\section{Isolation}

Observation was made at 24 hours intervals to detect any colony surrounded by a clear zone of inhibition. Both the organisms (inhibiting and inhibited) involved in antagonistic reaction were isolated aseptically and 


\section{OPTIMUM ANTIMICROBIAL METABOLITE PRODUCTION BY S. FULVOVIRIDIS}

transferred to slant of the same medium. The inhibiting and the inhibited colonies were marked as X-organisms and Y-organisms, respectively.

\section{Purification and maintenance of isolates}

The isolated organisms were purified through repeated plating. Streaking on nutrient agar and oat meal agar was done for these purposes. The purified isolates were then transferred to starch casein agar.

Primary screening by sensitivity spectrum analysis

Primary screening was made by sensitivity spectrum analyses test against 10 test organisms. Perpendicular streak plate method (Florey et al. 1949) was used for this purpose.

\section{Test organism}

In the present study, to screen the anti-microbial activity of microbial secondary metabolites 10 human pathogenic bacteria were used as test organisms. Among 10 human pathogens 6 were Gram negative - Shigella dysenteriae ss (AE 14612), Shigella sonnei (CRL, ICDDR, B), Salmonella typhi (AE14296), Vibrio cholerae (AE14748), Escherichia coli (ATCC25922), Pseudomonas aeruginosa (CRL, ICDDR, B) and 4 were Gram positive - Bacillus cereus (BTCC19), Staphylococcus aureus (ATCC6538), Bacillus subtilis (BTTC17), and Bacillus megaterium (BTTC18).

\section{Primary screening}

Three different media namely nutrient agar (NA) medium, starch casein agar (SCA) medium and Czapek Dox Agar (CDA) medium were used for primary screening. In each case, the melted medium was poured into petri plate and allowed to solidify. The isolate was streaked across the surface of the agar medium at the middle position of the plate and incubated at $37^{\circ} \mathrm{C}$ for growth. After growth, the test organisms were streaked perpendicularly. A space of 2-3 mm was kept between two streaks. Then the plates were incubated at $37^{\circ} \mathrm{C}$ for the growth of the test organisms. The plates were then observed for organisms sensitive to the metabolites produced by the isolates. A clear zone of inhibition appeared against those organisms.

\section{Identification}

The selected isolate MU9 was identified on the basis of morphological, cultural and physiological behaviors. These characteristics were compared with 
UDDIN ET AL.

standard description of Bergey's Manual of Determinative Bacteriology (Buchanon and Gibbons 1974).

Optimization of culture conditions for maximum production of antibiotic

The organisms which showed a considerable inhibition to the test organisms in primary screening, were selected for mass culture in liquid media. In a solid media an organism may produce an antimicrobial metabolite but it may not do so in liquid media. The production of an antibiotic may be influenced by different types of factors such as composition and $\mathrm{pH}$ of media, incubation period, temperature and condition (shaking or stationary). So, the maximum yield of an antibiotic depends on the optimization of these factors.

\section{Antibiotic assay by agar cup plate method}

In performing the sensitivity spectrum analyses by agar cup plate method, nutrient agar plates were heavily seeded $\left(2.7 \times 10^{3}\right.$ cells $\left./ \mathrm{ml}\right)$ uniformly with the test organisms. Then a hole was made in media by gel cutter in sterile condition. Then one drop of melted agar was poured into hole and allowed to solidify to make a base layer. After that specific amount of culture filtrate $(0.1 \mathrm{ml})$ was poured into the hole. Then plates were kept at low temperature $\left(4^{\circ} \mathrm{C}\right)$ for $2-4$ hours to allow maximum diffusion. The plates were then incubated at $37^{\circ} \mathrm{C}$ for 24 hours at inverted position to allow maximum growth of the organisms. The antibacterial activity of the test agent is determined by measuring the zone of inhibition expressed in milimeter in diameter (Barry 1976). The experiment was carried out more than once and mean of reading was recorded.

\section{Establishment of suitable culture medium}

Four different media (Medium A: Beef extract $3 \mathrm{~g}$, Peptone $5 \mathrm{~g}, \mathrm{NaCl} 5 \mathrm{~g}$, Dist. Water $1000 \mathrm{ml}$; Medium B :Yeast extract $0.2 \%$, Glucose $1.0 \%, \mathrm{~K}_{2} \mathrm{HPO}_{4}$ $0.1 \%, \mathrm{NaCl} 0.5 \%$; Medium C : Beef extract $0.75 \%$, Peptone $0.25 \%, \mathrm{NaCl} 1.5 \%$, $\mathrm{KCl} 1.0 \%, \mathrm{MgCl}_{2} 1.0 \%, \mathrm{FeSO}_{4} 1.0 \%$; Medium D: Corn steep liquor $0.2 \%$, Glucose $1.0 \%, \mathrm{~K}_{2} \mathrm{HPO}_{4} 0.1 \%, \mathrm{NaCl} 0.5 \%$ ) were prepared for antibiotic production. The $\mathrm{pH}$ of media was adjusted at $7.0 .150 \mathrm{ml}$ of the medium was taken in each $500 \mathrm{ml}$ conical flask. Each type of the medium was prepared in duplicate. Then the sterile media were inoculated with the specific organisms at $10 \%$ inoculum potential $(15 \mathrm{ml})$ and incubated at $37^{\circ} \mathrm{C}$. The product was assayed by agar cup method at an interval of three days and continued up to six days. 


\section{OPTIMUM ANTIMICROBIAL METABOLITE PRODUCTION BY S. FULVOVIRIDIS}

\section{Optimization of incubation period}

The effect of incubation periods on the antibiotic production by selected isolates was also studied. For this, $50 \mathrm{ml}$ of selected medium was taken in each $100 \mathrm{ml}$ conical flask and autoclaved. After cooling the broth medium was inoculated with equal quantity of inoculums, incubated at $37^{\circ} \mathrm{C}$ for $2,4,6$ and 8 days. Then the culture filtrate was assayed for antibiotic production.

\section{Optimization of incubation temperature}

After inoculation the culture medium with optimum $\mathrm{pH}$ was incubated at different temperatures such as $27^{\circ} \mathrm{C}, 30^{\circ} \mathrm{C}, 35^{\circ} \mathrm{C}, 40^{\circ} \mathrm{C}$, and $45^{\circ} \mathrm{C}$ for optimum incubation period. The culture filtrate was assayed for maximum antibiotic production by agar cup plate method.

\section{Optimization of media $\mathrm{pH}$}

To observe the effect of $\mathrm{pH}$ on antibiotic production, the selected medium was prepared at different $\mathrm{pH}(6.0,7.0,8.0,9.0,10.0$ and 11.0), dispensed $50 \mathrm{ml}$ per $100 \mathrm{ml}$ conical flask and autoclaved. Then the medium was inoculated and incubated at $37^{\circ} \mathrm{C}$ for optimum days. After incubation the culture filtrate was assayed for antibiotic production.

\section{Optimization of carbon sources}

The production of antibiotic under different carbon sources was studied in the selected culture medium. At a concentration of $1 \%$ four carbon sources (glucose, fructose, sucrose, starch) were added to the selected medium and after specific period of incubation the culture media were filtered and assayed for antibiotic production.

\section{Optimization of stationary and shaking incubation condition}

To determine the effect of stationary and shaking conditions broth medium was inoculated and incubated in both stationary and shaking conditions keeping all other experimental conditions at optimum. After specific period the culture media were filtered and assayed for antibiotic production.

\section{Production and recovery of antimicrobial metabolite}

\section{Fermentation}

For fermentation selected media were prepared and sterilized. Then inoculated with $5-10 \%(\mathrm{v} / \mathrm{v})$ of inoculum of selected strain MU9. All optimum conditions were maintained for maximum production. 
UDDIN ET AL.

\section{Isolation of antimicrobial agent}

The isolation of the antibiotic from the culture broth was achieved by extraction with an organic solvent not completely miscible with water. In this case the solubility of the antibiotic in different organic solvent was first investigated in order to find out a suitable solvent. The solvents used were petroleum ether, nbutanol, chloroform and benzene. For solvent- solvent partitioning of product the fermented product was gently shaken in a separating funnel with almost equal volume of pure petroleum ether, which is immiscible with aqueous alcohol. The mixture was then kept for several minutes for separating of the organic layer from the aqueous phase. The materials of the crude extract were partitioned between the two phases depending on their affinity towards their respective solvents. The organic layer was separated and collected in a conical flask and the process was repeated thrice. After collection of organic phase, the aqueous phase thus obtained was further extracted with other organic solvents like as n-butanol, chloroform and benzene in the same way usually of increasing polarity. Finally all the fractions were collected separately and dried and tested their anti-microbial efficacy.

\section{Studies of the stability of the antimicrobial metabolite}

Stability at different $\mathrm{pH}$

Twenty five $\mathrm{ml}$ of potent culture filtrate was taken in $50 \mathrm{ml}$ conical flask in duplicates and the $\mathrm{pH}$ of the filtrate was adjusted at $\mathrm{pH} 3,5,7,9,11$ by adding buffer solution. Then the flasks were kept inside the refrigerator for few hours and then the antibiotic was extracted by best solvent and assayed by agar cup plate method.

\section{Stability at various temperatures}

Twenty five $\mathrm{ml}$ of potent culture filtrate was taken in a $50 \mathrm{ml}$ conical flask in duplicates and heated in water bath at different temperature $\left(60^{\circ} \mathrm{C}, 70^{\circ} \mathrm{C}, 80^{\circ} \mathrm{C}\right.$, $90^{\circ} \mathrm{C}, 100^{\circ} \mathrm{C}$ and autoclave temperature $121^{\circ} \mathrm{C}$ ) for half an hour. Then the antibiotic was extracted with the best solvent (chloroform) and assayed by agar cup plate method.

\section{RESULTS AND DISCUSSION}

Primarily, 15 soil samples were collected from different chili fields in Chittagong, Bangladesh. Then the soil samples were examined by pour plating technique on three different media namely- nutrient agar medium, oat meal agar 


\section{OPTIMUM ANTIMICROBIAL METABOLITE PRODUCTION BY S. FULVOVIRIDIS}

medium and starch casein medium to find out any antagonistic microorganisms present. Following incubation, 14 antagonistic microbes (actinomycetes and bacteria) surrounded by a zone of inhibition and the inhibited ones were isolated. These were purified and preserved and the inhibiting isolates were tested for their antimicrobial activity.

Primary screening of the isolates

On the basis of their better antimicrobial activity against 10 pathogenic test organisms in three different media, the actinomycetes isolate MU9 was finally selected for detailed study. The sensitivity spectrum analyses test on nutrient agar medium revealed that the antimicrobial agent produced by the isolate MU9 was active strongly against Staphylococcus aureus, Bacillus subtilis, Bacillus cereus, Shigella sonnei, and weakly active against Shigella dysenteriae, Vibrio cholerae, Pseudomonas aeruginosa, Bacillus megaterium and Salmonella typhi and inactive against Escherichia coli . Chhiaki et al. (2007) also reported wide spectrum antimicrobial agent production by actinomycete isolate.

\section{Identification of the selected isolate}

On the basis of their morphological, cultural and biochemical characteristics, the actinomycetes isolate MU9 was found to belong to the genus Streptomyces. It was provisionally identified as Streptomyces fulvoviridis.(Buchanon and Gibbons 1974).

Optimization of culture conditions for maximum production of antimicrobial metabolite

Suitable medium and optimum incubation period

Among the four media used the medium-C was found suitable for antimicrobial metabolite production (Fig: 1). Following medium selection other tests were done on it. Streptomyces fulvoviridis exhibited a wide range of antimicrobial activity (zone of inhibition) against different test organisms. The highest activity was found against Shigella sonnei and Staphylococcus aureus after 4 days of incubation (Fig: 2) which is very close to a report describing the maximum of antimicrobial activity at 5 th day of incubation by Streptomyces sp. ( Yucel and Yamac 2010 ).

\section{Effect of incubation temperature and $\mathrm{pH}$ on antimicrobial metabolite production}

The actinomycete isolate Streptomyces fulvoviridis exhibited maximum antimicrobial metabolite production at $35^{\circ} \mathrm{C}$ (Fig: 3). It also showed maximum 
antimicrobial activity against Staphylococcus aureus (zone of inhibition $34.5 \mathrm{~mm}$ ) at $\mathrm{pH} 8.0$ (Fig: 4) which is very closely related to the observations of Jaiinpon et al. (2004) in actinomycetes.

\section{Effect of carbon sources on the production of antimicrobial metabolite}

Among the four carbon sources starch has significant effect on the production of antimicrobial metabolite which results in maximum activity against Bacillus subtilis (zone of inhibition $28.5 \mathrm{~mm}$ ) (Fig: 5).

Effect of incubation condition (stationary/shaking) on antimicrobial metabolite production

Shaking incubation condition was found optimum for the production of antimicrobial metabolite as compared to stationary culture (Fig: 6). This result complies with the report which described better bioactive metabolite production at shaking condition by Streptomyces sp. 201 (Thakur et al. 2009).

\section{Determination of $\mathrm{pH}$ and temperature stability of the antimicrobial metabolite}

The activity of the antimicrobial metabolite was found to be stable up to $\mathrm{pH} 11.0$ (Fig: 8) and temperature at $100^{\circ} \mathrm{C}$ (Fig: 7) which corresponds to the report on heat stable active component production by Streptomyces (Yucel and Yamac 2010).

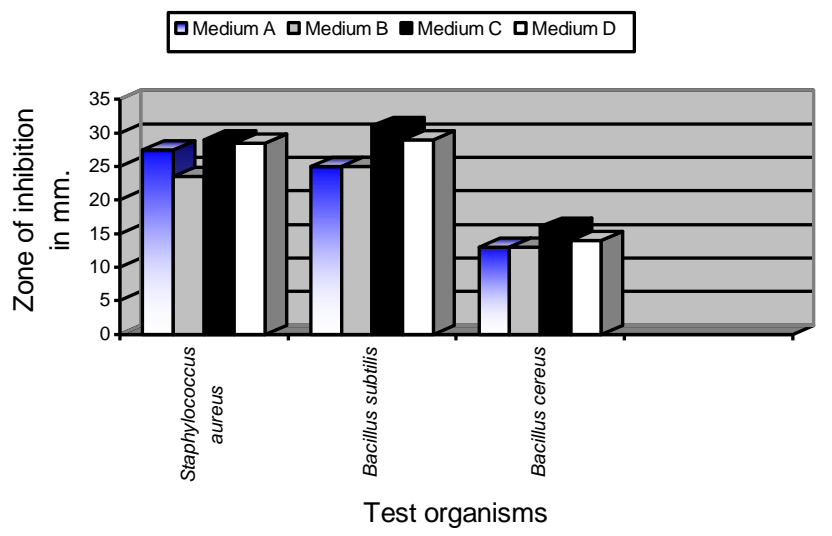

FIGURE 1: PRODUCTION OF ACTIVE AGENTS IN DIFFERENT CULTURE MEDIA BY STREPTOMYCES FULVOVIRIDIS 
OPTIMUM ANTIMICROBIAL METABOLITE PRODUCTION BY S. FULVOVIRIDIS

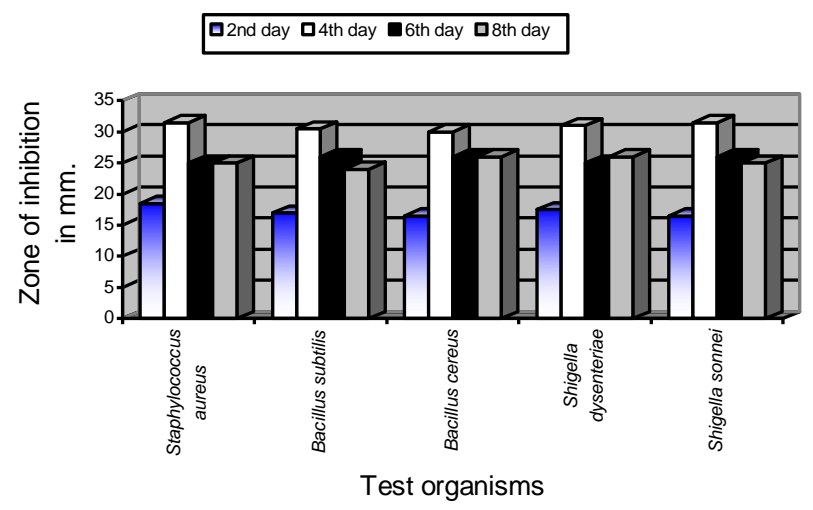

FIGURE 2: PRODUCTION OF ACTIVE AGENTS AT DIFFERENT INCUBATION PERIODS BY STREPTOMYCES FULVOVIRIDIS

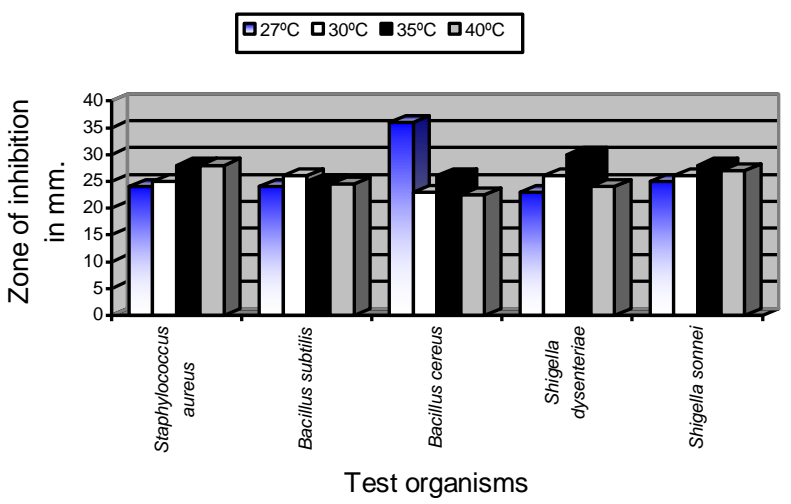

FIGURE 3: PRODUCTION OF ACTIVE AGENTS AT DIFFERENT INCUBATION TEMPERATURES BY STREPTOMYCES FULVOVIRIDIS 


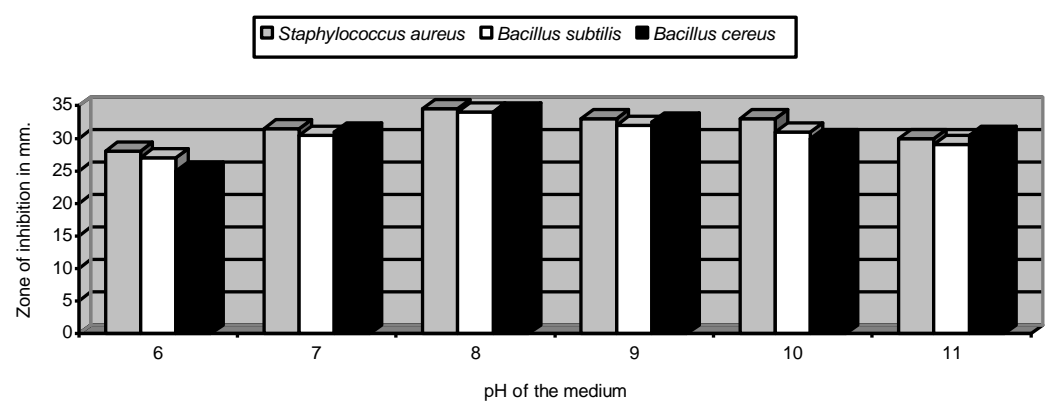

FIGURE 4: PRODUCTION OF ACTIVE AGENTS AT DIFFERENT pH BY STREPTOMYCES FULVOVIRIDIS

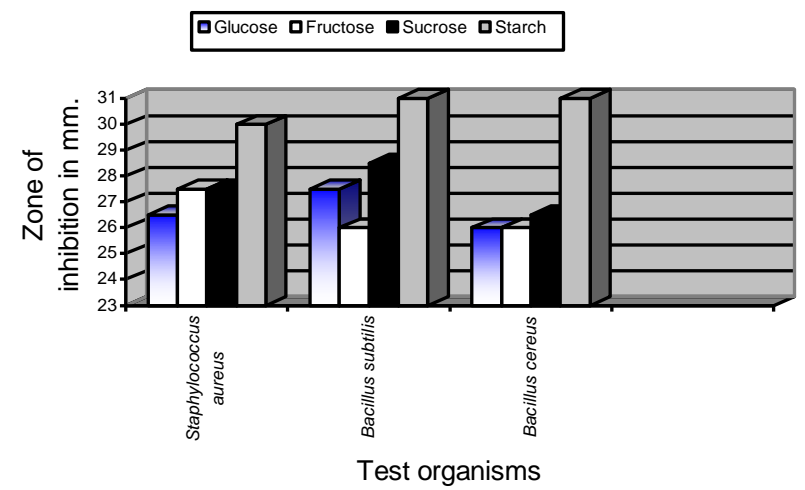

FIGURE 5: PRODUCTION OF ACTIVE AGENTS IN PRESENCE OF DIFFERENT CARBON SOURCES BY STREPTOMYCES FULVOVIRIDIS 
OPTIMUM ANTIMICROBIAL METABOLITE PRODUCTION BY S. FULVOVIRIDIS

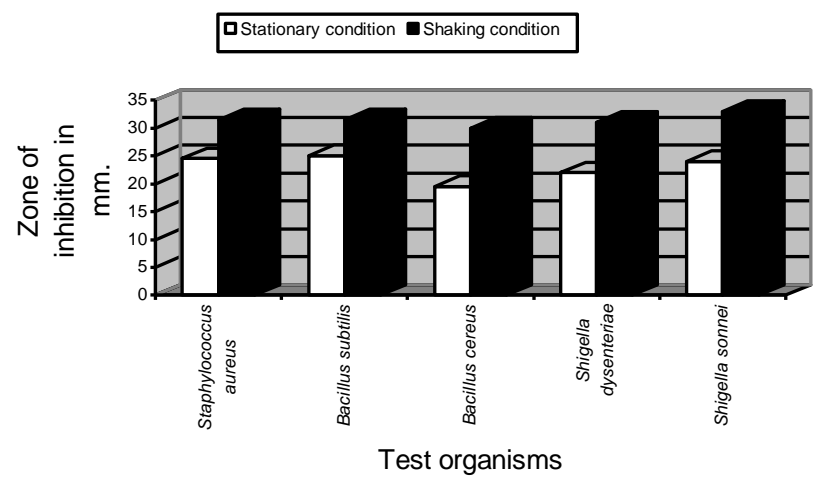

FIGURE 6: PRODUCTION OF ACTIVE AGENTS AT STATIONARY AND SHAKING CONDITIONS BY STREPTOMYCES FULVOVIRIDIS

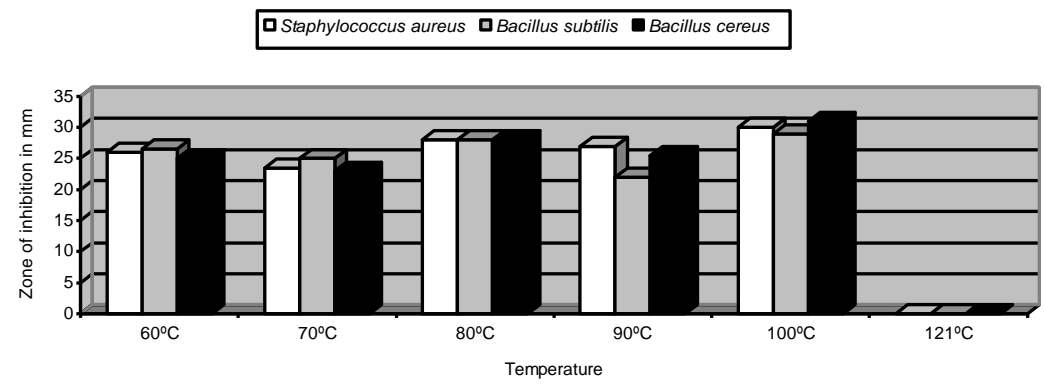

FIGURE 7: STABILITY OF THE ACTIVE METABOLITE PRODUCED BY STREPTOMYCES FULVOVIRIDIS AT DIFFERENT TEMPERATURES. 


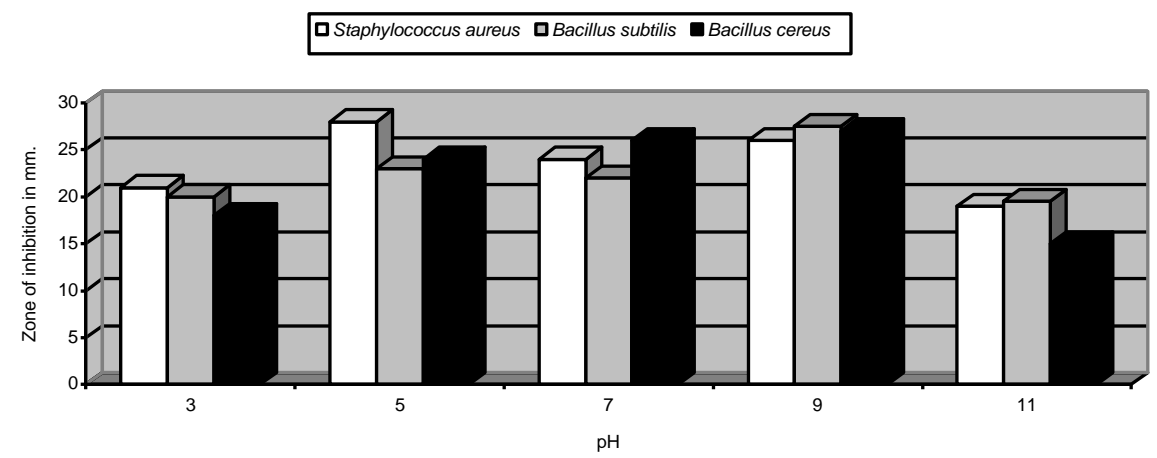

FIGURE 8: STABILITY OF THE ACTIVE METABOLITE PRODUCED BY STREPTOMYCES FULVOVIRIDIS AT DIFFERENT $\mathrm{pH}$.

\section{REFERENCES}

ATLAS R. M. 1997. Principles of Microbiology, $2^{\text {nd }}$ edn, WCB/McGraw-Hill, New York. 751pp.

BARRY, A. L. 1976. The Antimicrobial Susceptibility Test, Principle and Practices, 4th edition, ELBS, London. 180 pp.

BUCHANON, R.E. AND GIBBONS, N.E.1974. Bergey's Manual of Determinative Bacteriology, $8^{\text {th }}$ ed. Williams and Wilkins Co. Baltimore. $759 \mathrm{pp}$.

CHHIAKI, I., NAOKO, K., MASAZUMI, K., TAKESHI, K. AND NAOKO, H. 2007. Isolation and characterization of antibacterial substances produced by marine actinomycetes in the presence of seawater. Actinomycetologica, 21: 27-31.

DAKORA F., AND PHILLIPS, D. 2002. Root exudates as mediators of mineral acquisition in low-nutrient environments. Plant and Soil. 245:35-47.

FLOREY, H.W., CHAIN, E.B., HEATLY, N.G., JENNININGS, M.A., SAUNDERS, A.G., ABRAHAM, E.P. AND FLOREY, M.E.1949. Antibiotics. Oxford University Press. 1:273-287.

JAIINPON, J., CHEEPTHAM, N., SONTHICHAI, W. AND LUMYONG, S. 2004. Optimization of antifungal antibiotic production of Actinomycetes from cave soil. Papers Presented at the $30^{\text {th }}$ Congress on Science and Technology of Thailand, 19-21 October 2004, Bangkok. 
KUSTER, E. AND WILLIAMS, S.T.1964. Selection of media for isolation of streptomycetes. Nature, London, 202:928-929.

OMURA, S., IKEDA, H., ISHIKAWA, J., HANOMOTO, A., TAKAHASHI, C., SHINOSE, M., TAKAHASHI, Y., HORIKAWA, H., NAKAZAWA, H., OSONOE, T., KIKUCHI, H., SHIBA,Y., SAKAKI, T. AND HATTORI. M. 2001. Genome sequence of an industrial microorganism Streptomyces avermitilis deducing the ability of producing secondary metabolites. Proceedings Natural Academic Science USA. 21:1221512220.

OSBORNE, M., GROSSMAN, T., AUGUST, P. AND MACNEIL, I. 2000.

Tapping into microbial diversity for natural products drug discovery. ASM News. 7:66.

PANDEY, B., GHIMIREL, P., PRASAD, V., THOMAS, M., CHAN, Y. AND OZANICK, S. 2002. Studies of the antimicrobial activity of the actinomycetes isolated from the Khumby region of Nepal (Thesis). Department of Bacteriology, University of Wisconsin - Madison, Madison, Wisconsin. (http://grad.uprm.edu/tesis/riverarivera.pdf)

PELCZAR, M.J. AND REID, R.D.1974. Microbiology. Tata McGraw-Hill Pub. Co. Ltd. pp. 71-72.

RONDON, M., RAFFEL, S., GOODMAN, R. AND HANDELSMAN. J. 1999. Toward functional genomics in bacteria: analysis of gene expression in Escherichia coli from a bacterial artificial chromosome library of Bacillus cereus. Microbiology. 96:6451-6455.

THAKUR, D., BORA, T.C., BORDOLOI, G.N. AND MAZUMDAR, S. 2009. Influence of nutrition and culturing conditions for optimum growth and antimicrobial metabolite production by Streptomyces sp. 201. J. Med. Myc. 19: 161-167.

YUCEL, S. AND YAMAC, M. 2010 .Selection of Streptomyces isolates from Turkish karstic caves against antibiotic resistant microorganisms. Pak. J. Pharm. Sci., 23:1-6.

Manuscript received on 5. 8. 2010; Accepted on 29.9.11

The Chittagong University Journal of Biological Sciences, Vol. 5 (1 \& 2). Page No:63-75 